NBER WORKING PAPER SERIES

MANDATES AND THE AFFORDABILITY OF HEALTH CARE

\author{
Sherry A. Glied \\ Working Paper 14545 \\ http://www.nber.org/papers/w14545 \\ NATIONAL BUREAU OF ECONOMIC RESEARCH \\ 1050 Massachusetts Avenue \\ Cambridge, MA 02138 \\ December 2008
}

This research was funded by the Economic Research Initiative on the Uninsured, Robert Wood Johnson Foundation. The views expressed herein are those of the author(s) and do not necessarily reflect the views of the National Bureau of Economic Research.

NBER working papers are circulated for discussion and comment purposes. They have not been peerreviewed or been subject to the review by the NBER Board of Directors that accompanies official NBER publications.

(C) 2008 by Sherry A. Glied. All rights reserved. Short sections of text, not to exceed two paragraphs, may be quoted without explicit permission provided that full credit, including $\odot$ notice, is given to the source. 
Mandates and the Affordability of Health Care

Sherry A. Glied

NBER Working Paper No. 14545

December 2008

JEL No. I18,I32,I38

\begin{abstract}
$\underline{\text { ABSTRACT }}$
This paper examines the economic rationale of affordability exemptions in the context of a health insurance mandate. On its face, an affordability exemption makes little sense -it exempts people from purchasing a good that policymakers believe benefits them. I provide an economic definition of affordability and discuss how it is implemented in the contexts of food, housing, and health care. Affordability standards are frequently used in food and housing policy making, but both empirically and theoretically health care operates quite differently than do these other merit goods. These differences help explain why the use of affordability in health policymaking is so different from its use in these other contexts. I conclude with a discussion of the relationship between mandates and exemptions in other health care systems.
\end{abstract}

\author{
Sherry A. Glied \\ Mailman School of Public Health \\ Columbia University \\ Department of Health Policy and Management \\ 600 West 168th Street, Room 610 \\ New York, NY 10032 \\ and NBER \\ sag1@columbia.edu
}


In 2006, Massachusetts passed its path-breaking universal health care reform, which incorporates a mandate requiring that all state residents obtain coverage. The plan envisioned that subsidies would be available to assist low- and moderate-income residents in purchasing the newly-mandated coverage. The state legislature, however, was unable to fund the necessary subsidies in full. To address this problem, the State determined that the mandate would apply only to those deemed to be able to afford coverage. The regulatory agency responsible for administering the new program, the Commonwealth Connector Authority, was required to develop an affordability schedule, based on incomes and premium costs, that declared who would be exempt from the mandate. In total, about 1-2\% of Massachusetts residents were deemed exempt from the mandate in 2007 (http://www.statecoverage.net/programs-massachusetts.htm).

The term affordability has long been used as a descriptive measure in analyses of medical care costs. For example, a 1999 Commonwealth Fund study described those who "skipped needed medical care in the past year because of cost" as people who "can’t afford to get sick.” (Budetti et al., 1999) It is also often used in contexts involving health insurance. In research examining how changes in health care costs affect the number of people who hold health insurance, Todd Gilmer and Richard Kronick (2005) develop an "affordability index", which compares per capita health spending and median incomes. They find that this affordability index strongly tracks the uninsurance rate. Similarly, studies of the efficacy of tax credits in leading to voluntary expansions of coverage also consider the "affordability of individual health insurance" in making forecasts (Hadley and Reschovsky, 2002). 
There is also a long tradition of using assessments of affordability in making allocations of publicly supported goods and services. The allocation of welfare-based income support and food stamps (among other benefits) is based on an assessment of the affordability of food. Housing policy also uses an explicit affordability rule in allocating subsidies.

Despite these compelling descriptive and prescriptive precedents, the use of the affordability standard in the context of the Massachusetts mandate is quite novel. Unlike the food stamps and housing support examples, residents of Massachusetts who do not meet the affordability standard will not be provided with public subsidies or benefits rather, they will be exempted from the requirement to purchase health insurance coverage in the private market and may remain uninsured. This paper examines the economics behind the idea of affordability, describes how the idea of affordability is implemented in practice, evaluates the rationale of the affordability exemption by comparing health care services and other merit goods, and considers alternative strategies for addressing flaws introduced by an affordability exemption in the context of a mandate.

\section{The Economics of Affordability}

In standard welfare economics, individual's choices over goods and services are the basic currency of analysis. The accepted measure of preferences is the willingness of an individual to pay for a good or service. Economists are generally not interested in why someone is unwilling to pay for a good or service.

The term affordability as used in ordinary life implies that the primary reason that someone chooses not to purchase a good or service is that the person does not have the 
ability to pay for it - that is, it distinguishes between non-purchase related to income and non-purchase related to preferences. Thus, for example, when the "Dress Like Lindsay Lohan” website urges readers “if you can't afford to spend thousands on a purse you'll carry once, find a knock-off," the underlying assumption is that the reader would want to buy such a purse if only the resources were available (http://www.ehow.com/how_2098814_dress-like-lindsay-lohan.html).

The ordinary use of the term affordability, however, is insufficient for most public policy purposes. It is a descriptive term, meaning essentially the same thing as that a good is normal -consumers would buy more of it if their income increased. The public policy use of the term affordability is normative, not descriptive. Policymakers are concerned about whether a household can afford to purchase a pre-defined quantity of a merit good. A household is said to "afford" such a purchase if it would be left with enough income to meet its other socially-defined minimum needs. Thus, as Hancock (1993) explains, "this is the essence of the concept of affordability: what has to be foregone in order to obtain housing [the merit good] and whether that which is foregone is reasonable or excessive in some sense.” (at p. 129). Recent work has extended Hancock’s analysis to the context of health insurance (Bundorf and Pauly, 2006) and health care (Russell, 1996).

Hancock illustrates his definition of affordability using a simple diagram (see Figure 1, adapted to the health care/insurance context). People whose consumption patterns fall in the A area, cannot afford the socially desirable minimum quantity of either health care or other merit goods. Those in the B and C area are consuming more than the socially adequate quantities of other merit goods and of health care, respectively, but do not have 
enough income to purchase adequate quantities of both, even if they re-arrange their spending patterns. Those in the F area can afford, and are consuming, more than socially adequate levels of health care and of other merit goods. Those in the D and E areas are consuming more than socially adequate quantities of other merit goods (area D) or of health care (area E), and could afford to purchase adequate quantities of health care (area D) or of other merit goods (area E) but choose not to do so.

Hancock's formulation describes several groups of interest in the context of health care and health insurance affordability. Those in areas A and B are non-afforders. They have neither the ability nor willingness to pay for the socially defined minimum quantity of health care. Those in area $\mathrm{D}$ can be described as afforders. This group buys more than the social minimum level of non-health goods, and chooses not to purchase the social minimum of health care. Prior research has shown, for example, that uninsured people spend more on housing, alcohol, and tobacco than do insured people with comparable income levels (Levy and DeLeire, 2003). Uninsured people with high spending on these non-health consumption items may fall into area $\mathrm{D}$ (if their excess spending is sufficiently high to allow them to pay for health insurance) or into area B (if it is not). In either case, this group's willingness to pay for health care falls below its ability to pay.

Some, often uninsured people, fall into area $\mathrm{C}$ or area $\mathrm{E}$. They spend very large amounts on health care, neglecting other socially necessary purchases. For example, prior to the passage of Medicare Part D, Representative Kucinich reported that "Seniors in my district are splitting pills to make their prescriptions last and going without meals to cover refill costs," (Baglole, 2003) Russell (1996) similarly argues that in low income countries, unexpected health expenses may lead families to forego school 
payments and to sell productive assets. Bundorf and Pauly (2006) refer to this group as “insured non-afforders.” For this group, willingness to pay exceeds ability to pay.

\section{Operational Definitions of Affordability}

The normative definition of merit good affordability described above is both challenging to implement empirically and from a policy design perspective. It requires defining, for each household, the minimum socially desirable level of consumption of the index merit good (i.e., health care) and of consumption of other merit goods; assessing the prices faced for each of these goods or services; and measuring income. This exercise is likely to be computationally daunting as a research project and intractable as a policy standard (for an example, see Renwick and Bergmann, 1993). Moreover, basing the standard of affordability on the prices of other merit goods as well as the index merit good means that subsidies associated with the index merit good also indemnify recipients against changes in the prices of other merit goods. From a policy design perspective, this cross-indemnification feature would make index good subsidies appear unexpectedly costly. Instead, analysts and policymakers have adopted a variety of more limited, shorthand rules for affordability.

The most well-developed affordability standard is that for food. The standard is based on a clearly defined minimum standard for the index good. Research conducted between 1905 and 1960 defined a set of nutritionally adequate bundles of food for household consumption and the Department of Agriculture adopted one of these bundles as its economy food plan (Fisher, 1992). The US poverty standard is based on the relationship of It then relates the price of this bundle to income. In 1950, the average American household spent about $1 / 3$ of its income on food. Based on these data, 
economist Mollie Orshansky of the Social Security administration argued that a family was poor if its income was less than 3 times the cost of purchasing this minimally adequate food bundle (Fisher, 1992). The underlying assumption is that a low-income family that could afford to purchase food would need to spend the remaining $2 / 3$ of its income on other necessary goods. This measure of food affordability continues to be the basis of the federal poverty line today, although critics question its validity given that the share of food in household consumption has now fallen below 12\% (see Table 2).

The US Department of Housing and Urban Development similarly bases its criterion for housing affordability on a housing standard (adjusted to reflect family size), the cost of that standard (measured as local housing prices), and household income. A household is defined as able to afford housing if it pays "no more than 30 percent of its annual income on housing. Families who pay more than 30 percent of their income for housing are considered cost burdened and may have difficulty affording necessities such as food, clothing, transportation and medical care.” http://www.hud.gov/offices/cpd/affordablehousing/

Bundorf and Pauly (2006) propose a "behavioral" definition of affordability in the context of health insurance. They argue that health insurance is affordable to a family if $50 \%$ or more of similarly situated families purchase insurance. Their definition of "similarly situated" incorporates family income, family composition, and measures of the price of health insurance (either prices or expected expenditures, unadjusted for geography). As Bradley (2008) points out, unobserved heterogeneity in the prices faced by different families (both those in the group and non-group markets) makes this behavioral calculation suspect. For example, people who do not hold coverage but 
appear to be able to afford it may work in jobs that do not provide coverage or that offer coverage with very high premium sharing, while those who do not hold coverage may be employed in jobs that offer coverage with low premium sharing. It is particularly challenging to identify insured non-afforders using available data. Information on insurance premiums can be used to impute a price of insurance for those who are uninsured, but no available data provide information on the price of insurance paid by those who currently hold coverage.

The Commonwealth Connector in Massachusetts determines rules of affordability each year (http://www.masslegalservices.org/docs/Affordability_Information_Sheet_English.pdf). It defines affordability according to the ability of individuals and families to buy coverage offered through the Connector. All coverage offered through the Connector meets minimum coverage standards and rates vary by age, but not by health status. The Connector's affordability standards are based on family income, family size, age, and region of residence in the state. They are calculated by assuming that a household with income over 300\% FPL should not be required to spend more than a fixed percentage (about 5\%-8\%, depending on income category) of its income on health insurance. The Connector's affordability rule avoids the problems identified by Bradley (2008) because the cost of insurance available to an individual of a given age through the Connector is known with certainty.

In sum, operational definitions of affordability in these different contexts are quite similar. They typically define a minimum standard for the index good only (although this minimum standard may vary with household characteristics) and they consider only 
incomes and measures of the price of the index good. In all three contexts, the affordability standards are normative - they combine a normatively determined minimum standard of the index good and a normatively determined share of income that this good may comprise. Only the prices of the index good and the incomes of the population of interest are determined objectively.

III. The Rationale of a Health Care Affordability Exemption: Comparing Health Care and Other Merit Goods

While the operational definition of health care affordability resemble those used in other contexts, health care affordability differs from affordability in other contexts in several important ways ${ }^{1}$. These differences help explain the economic logic behind an affordability exemption in this context.

\section{Ability to Pay and Willingness to Pay}

One difference between health care and other merit goods occurs in the relationship between willingness to pay and ability to pay. In the context of food, relatively few people with the ability to pay for the socially desirable minimum bundle are unwilling to do so. The population of area $\mathrm{D}$ is small. For example, among those with incomes between $100-200 \%$ of the poverty line in the U.S., who can presumably afford food, less than 4\% reported food insufficiency (Gundersen and Gruber, 2001). One reason for the use of in-kind transfers of food and housing may be that policymakers fear that if income

\footnotetext{
${ }^{1}$ Note that there is an extensive literature on housing affordability which, among other things, points out how much more complex it is to determine housing affordability than food affordability. The distinctions between food and housing are not, however, the same as the differences between health care and these other merit goods, so I am not discussing them here.
} 
transfers were substituted, the size of area D would grow - that is, people would use income transfers to buy other goods in preference to purchasing the socially desirable minimum bundle of food and housing. At the same time, few people are willing to pay much more for food than they are able to pay (area E is small).

The case of housing is somewhat different. Few people who can afford to purchase housing choose to go homeless instead (area $\mathrm{D}$ is small). On the other hand, many people live in housing that is normatively unaffordable to them. HUD estimates that 12 million people now spends more than $50 \%$ of their income on housing (http://www.hud.gov/offices/cpd/affordablehousing/index.cfm). In some cases, these purchasing non-afforders go without other merit goods to pay for housing. For example, low income households reporting food insufficiency pay nearly 1/3 more for housing than do similar households that are not food insufficient ${ }^{2}$. In other cases, the apparent mismatch occurs because of errors of classification (Thalmann, 1998).

In health care, the number of people who fall into both areas $\mathrm{D}$ and $\mathrm{E}$ is quite large. Bundorf and Pauly (2006) estimate that about half of uninsured people could afford to purchase insurance coverage (area D). Similarly, many other uninsured families can afford coverage because they are eligible for free or low-cost public insurance coverage that they have not taken up. It is more difficult to ascertain the number of people who spend more than they can afford on health care and insurance. Based on Bundorf and Pauly's (2006) estimates, roughly 10\% of privately insured people have health insurance but appear to be unable to afford it (area E), but this figure may reflect people who face exceptionally low prices for health insurance.

\footnotetext{
${ }^{2}$ Difference is not statistically significant however.
} 
Data on health care spending by people without health insurance provides another measure of the number of people willing to pay more for care than they can afford. I use the 2005 MEPS to look at expenses for health care among the uninsured (Table 1). I use a standard of $1.5 \%$ of income as the threshold for underconsumption of care and a threshold of 30\% of family income as a threshold for non-affordability. I repeat the analyses using out-of-pocket expenses for care. I find that about 1/2 of all uninsured individuals and families incurred total health expenses of less than 1.5\% of income in a year, and about $2 / 3$ spent less than $1.5 \%$ of income out of pocket on health care. At the same time, many uninsured people incur substantial health care bills. More than $1 / 4$ of low income (100-125\% FPL) individuals incurred health care expenses equivalent to more than $30 \%$ of their total income and nearly $1 / 4$ spent $30 \%$ of their income on out-ofpocket medical expenses. High medical spending was not unusual even among higher income uninsured people. Among uninsured people with incomes over 400\% FPL, 13\% incurred expenses above $30 \%$ of income and about $10 \%$ spent over $30 \%$ of income outof-pocket. To put these figures into perspective, $30 \%$ of income for a person at $100 \%$ FPL would be about $\$ 3000$, easily enough to purchase a health insurance policy. The figures for high spending are substantially lower among families, where high health spending for one member is offset by low health spending for another. Nonetheless, about $7 \%$ of uninsured families incurred health expenses exceeding 30\% of their income and about $2 \%$ spent more than $30 \%$ of family income on health care. In a developing country context, Russell (1996) finds that very substantial proportions of those who need care forego other necessities to pay for it. 
The large number of people who apparently can afford coverage - and may spend the price of coverage on out-of-pocket medical expenses -- but choose not to buy coverage reflects, in part, the failures of health insurance markets. If insurers cannot or do not charge premiums that accurately reflect an individual's risk status - either because regulations prohibit such rating or because the administrative costs of doing so are excessive - some healthy people who can afford current premiums will choose, instead, to remain uninsured. This adverse selection behavior can undermine the functioning of insurance markets and make it difficult to cross-subsidize high risk people. One important rationale for mandates is to compel uninsured afforders to purchase coverage and shore up this market (Glied, 2008). Unlike uninsured afforders who self-select out of coverage, those who do not participate in the insurance market because they cannot afford coverage do not contribute to adverse selection-induced market failure. From an insurance market perspective, they need not be compelled to participate in the insurance market.

\section{Health Care Demand and Insurance}

Much of the literature on affordability focuses on uninsured afforders. As the data above suggest, however, the mismatch between ability to pay and willingness to pay in this context goes in both directions. A substantial number of households spend much more than they can normatively afford on health care.

The literature on affordability in the health context refers sometimes to health care expenditures and sometimes to health insurance, a means of financing these expenditures. 
This aspect of the mismatch between ability and willingness to pay stems, in part, from the nature of the demand for health care and the distinction between these two concepts.

Both the willingness to pay for food and, as the Department of Agriculture assumed in its construction of the minimum food basket, the socially defined minimum basket of food are quite stable over time for a given individual. The same is true of housing. The value of medical care to an individual and the socially defined minimum quantity of health care, however, vary substantially over time as underlying health status varies.

The range in the cost of the minimum health basket for the same individual is enormous. Care at the most costly end of this range will be unaffordable to a substantial majority of the population. As Nyman (1999) points out, an important rationale for the purchase of insurance is to gain access to this necessary but unaffordable care. The access function of health insurance means that those who have purchased health insurance are unlikely to become purchasing non-afforders (area D).

As the data in Table 1 (and a voluminous literature on skewed health expenditures) suggest, the distribution of health care expenditures is highly varied and uncertain. Health insurance allows people to transform this uncertain distribution of medical expenses into a predictable premium. This premium encompasses the expected costs of treatment for very costly (unaffordably costly) low probability illnesses as well as the low costs of routine and preventive care. The premium will generally be greater than the mean of this distribution, because loading costs (and costs associated with moral hazard) are built into the premium.

The affordability of health care and of health insurance are formally related. An individual may be able to afford health insurance but be unable to afford all elements of 
the potential distribution of health care expenses. By contrast, if there were no loading, a person who could afford all elements of the distribution of health care expenses could necessarily also afford health insurance. Since the costliest elements of the distribution of health care expenses are many times greater than the mean of that distribution, and the loading rate is generally below 2, it will generally be the case that those who can afford all elements of the distribution of health care expenses can afford health insurance. The set who find health insurance affordable is a subset of those who find health care affordable.

The willingness to pay for health care and the willingness to pay for health insurance are not formally related in this way. At the moment of an extreme medical crisis, nothing is more important than health care, and families will willingly incur tremendous expense to treat an urgent illness. On the other hand, when health care needs are not pressing, many families will go without routine and preventive care. With respect to health spending, the same individual may appear as a purchasing non-afforder - buying very costly urgent care -- (area D) and a non-purchasing afforder - failing to buy routine and preventive care -- (area E) at different points in time, as health needs change while income remains constant.

Health insurance premiums provide future benefits but may not be a critical or salient expense at the time that they come due. Few families are likely to impoverish themselves to make health insurance premium payments, although they may be willing to pay substantially more than the premium amount for care in the event of a health catastrophe. For example, poor households who report food insufficiency are significantly less likely 
to hold health insurance than are other equally poor households (Gundersen and Gruber, 2001).

There is nothing analogous to health insurance in the market for other merit goods, such as food or housing (although home ownership comes closer). Each of these goods is salient and yields benefits at the point of purchase. Except for a tiny minority who suffer from addictions or disorders, we anticipate and observe that most people's ability to pay for these goods is largely consistent with their willingness to pay for them. The same is true of urgent medical care. It is hard to imagine public policymakers mandating the purchase of food, housing, or urgent care.

A second piece of the logic behind health insurance mandates is that people make inappropriate decisions in choosing whether to pay for care or for coverage. In the context of Figure 1, however, only those in Area D - who could afford insurance coverage but choose not to buy it - are behaving inappropriately with respect to insurance purchase. Those who cannot afford coverage do not even have the opportunity to make this inappropriate decision.

Uninsured non-afforders may, however, make other socially inappropriate health care purchasing decisions. The large proportions of uninsured individuals and families in Table 1 who spend only tiny amounts on medical care each year - less than the likely cost of routine and preventive care -- pose a distinct policy problem. Insurance that covers the socially desirable health care bundle - such as the Commonwealth Connector basic coverage package -effectively subsidizes the cost of these routine and preventive care services at the point of service through less than $100 \%$ cost-sharing. Mandate coverage encompasses these benefits because policymakers believe that they are 
underused. Those exempt from the mandate for reasons of unaffordability will not benefit from these implicit subsidies and will not increase their use of routine and preventive services.

\section{The Safety Net}

The social value of merit goods is reflected in the fact that both governments and charitable organizations provide a safety net of services for these goods. In each case, the safety net exists in parallel with a more formalized system that provides resources for the purchase of merit goods: soup kitchens and food stamps; homeless shelters and Section 8 vouchers; medical care in emergencies and public insurance programs. In each case, services provided through the formalized system are generally preferred to safety net services. Services provided through the safety net offer fewer choices, are usually of lower quality, and are less reliably available than formalized services. Most people would prefer to purchase their own selection of very basic food to relying on a soup kitchen, and would prefer living in their own housing, however shabby, to relying on a homeless shelter. Similarly, though perhaps less strikingly, obtaining medical services through insurance coverage is likely to be preferred to relying on emergency medical care.

The design of the health care safety net addresses a part of the health care affordability problems described above for people who lack insurance coverage. Like insurance, the safety net ensures that people have access to (some) services whose cost exceeds their income. It also works, in combination with bankruptcy laws, to protect people from impoverishing themselves to meet their immediate health care needs. As the 
data in Table 1 suggest, many families who incur substantial health care costs do not incur proportional out-of-pocket costs. The health care safety net, however, does not provide all the services included in the socially desirable health care bundle. In particular, it provides very limited routine and preventive health care.

Although the safety nets for food, housing, and medical care serve similar purposes, their nature is quite different. The services provided through the food and housing safety nets are not only of lower quality than analogous purchased goods, they are also inexpensive to produce and consumers would not be willing to pay much for them. By contrast, services provided for medical care in emergencies are among the costliest components of the health care bundle and consumers have (as suggested above) a higher willingness to pay for these services than for most other medical services.

All safety nets generate some moral hazard - some people who might be able to purchase goods on their own will rely on the safety net instead. The nature of the health care safety net, however, means that this behavior is more likely in the case of health insurance than in the case of food or housing. A final rationale for mandates is to avoid this type of "free-riding" on the safety net. The affordability exemption allows those who cannot pay for the cost of the safety net services they use to continue to use them at less than full cost.

IV. Rethinking Affordability in the Context of Mandates

A mandate affordability exemption, such as that in Massachusetts, serves an important political purpose. Governments who cannot fund adequate subsidies recognize that forcing lower middle income people to spend a large share of income on medical 
insurance would be unpopular and likely counterproductive. At second glance, however, the notion of an exemption seems outlandish. The government is saying that those who cannot afford health insurance do not need to have it. This seems a peculiar way to treat a merit good. It is hard to imagine a government telling people who cannot afford food that they are not compelled to eat!

As the discussion above suggests, however, there is economic logic behind an affordability exemption from the health insurance mandate. Three central purposes of a mandate are to stabilize the private insurance market; compel people who might delay or neglect to buy coverage to make rational purchasing decisions; and reduce free-riding with respect to the safety net (Glied, 2008). Uninsured non-afforders do not contribute to insurance market instability because they do not self-select out of the market. They do not make irrational insurance purchasing decisions - they fail to buy coverage primarily because they cannot afford it. They do not free-ride on the safety net, because they do not have the resources to pay for the safety net services that they do use.

While logical, however, an affordability exemption leaves one important social goal unaddressed. An exemption does nothing to improve the delivery of preventive and routine services to uninsured non-afforders. Uninsured non-afforders will continue to experience worse health and continue to use safety net services in inefficient ways. The affordability exemption makes sense only as a stop-gap measure, leaving a minute fraction of the population uninsured but allowing many of the benefits of the mandate to be realized during a brief interval before the state finds enough money to realize the full subsidy program. 
Unfortunately, however, the number of exempt non-afforders is almost certain to grow rapidly over time. This rapid growth in the number of non-afforders, too, reflects differences between health care and other merit goods.

\section{Affordability over Time}

Housing, food, and medical care are all normal goods, so demand for them rises with income. Food is income inelastic and has been declining as a share of consumption over time (Tobin, 1950). Housing is also income inelastic, in both cross-sectional and timeseries analyses, although housing has risen (slightly) as a share of consumption over time (Hansen, Formby, and Smith, 1998). Medical care, however, appears to be income elastic. In studies across regions, countries, or time, health care spending rises more than proportionally with income and, over time, health care spending has increased substantially as a share of consumption (Hall and Jones, 2007; Getzen, 2000). Increases in the cost of health care over time reflect a substantial willingness to pay for improvements in the quality (and convenience) of care and a correspondingly high rate of technological improvement.

The varying income elasticities of different merit goods are reflected in data on the composition of consumption over time (Table 2). Data on consumption patterns does not include consumption of medical care that is paid for by public insurance or by employersponsored insurance. I adjust for this by subtracting from the consumption data all medical care expenses, adding national per capita average health care spending as a measure of average medical care consumption, and adding national per capita average health care spending to income to reflect the taxes and wages foregone that fund this 
consumption. On average, the food share of consumption has fallen by nearly $2 / 3$ since 1950. The housing share of consumption has risen by 3 percentage points. The health care share of total consumption has risen by more than 10 percentage points.

The income elasticity of merit goods has implications for the determination of the social minimum bundle of each of these goods (Fisher, 1995). The food standard is least affected by changes in income, and has, correspondingly, changed little over time. Housing standards have increased over time, and a portion of the increase in unaffordability of housing can be attributed to changes in the standard of housing viewed as minimally adequate (Quigley and Raphael, 2004). The minimum socially acceptable standard of health care appears to increase briskly over time, as technologies improve and as average incomes rise. As the data for the past 60 years suggests, the proportion of average income consumed by the minimum acceptable standard of health care will almost certainly rise over time. In consequence, the fraction of the population who are deemed to find coverage unaffordable will likely increase, eventually undoing many of the benefits of the mandate. Below, I evaluate two strategies to address these flaws in the use of affordability exemptions.

\section{Affordability and the Content of Coverage}

The affordability exemption to a mandate is a binary rule - people either must have comprehensive insurance coverage or they may remain uninsured. An alternative strategy would be to use an affordability rule to vary the contents of mandated coverage.

Comprehensive health insurance provides coverage for both urgent care services and for routine and preventive care services. The safety net, however, provides some 
insurance-like protections for urgent care services to low and middle income people at relatively low cost. The components of the health care bundle that comprise these safety net medical services contribute substantially to both the price and value of comprehensive health insurance. While comprehensive health insurance also provides protection, and access, to socially desirable routine and preventive care, the cost of this extra protection is generally included within the same premium. Many people are neither able nor willing to pay a full premium to obtain services the most valuable of which would be available to them at lower cost through the safety net (Glied, 2003).

Rather than exempting this group of uninsured non-afforders from the coverage mandate altogether, an alternative strategy would be to mandate that they purchase a lower cost (and hence affordable) front-end bare-bones coverage package. Purchase of this package would provide those subject to this modified mandate with an incentive to use routine and preventive services and might improve the efficiency of use of the safety net. Depending on the normatively-determined threshold, the premium for this package might also defray a portion of the expected costs of using safety net services, particularly if the use of routine services led to increases (rather than decreases) in high cost treatment. A two-tiered mandate system would address the goal of ensuring that the entire population had incentives to use preventive and routine care and would also keep the entire population in the insurance pool, facilitating risk adjustment or insurance market reform strategies.

The Affordability Threshold 
A second strategy to improve the functioning of an affordability exemption would be to adjust it over time. Health care, while becoming more costly over time, also becomes more valuable over time, as quality increases. This is evident in data on the relationship between costs and coverage. Increases in the cost of health care do lead to reductions in coverage, but the elasticity of coverage with respect to the cost of care is well below 1 . Gilmer and Kronick (2005) estimate that a 1\% increase in health spending relative to personal income will lead to an increase of about 246,000 - or about $0.5 \%$-- in the number of people uninsured. People at all levels of the income distribution are willing to pay more for better care.

As critics of the US poverty standard have argued, there is no reason to enshrine in policy the spending patterns of fifty years ago. The declining share of food in family budgets negates the logic of a poverty standard calculated as 3 times the cost of the basic food bundle. Likewise, increases in the share of health care in national income might lead to adjustments in the affordability threshold. Such adjustments, however, would have to consider the original normative definition of affordability and take into account both changes in the cost of health care and changes in the prices and standards of other merit goods.

\section{Conclusions}

The Massachusetts affordability exemption is the first use of this standard for normative policy making in the United States. There is a long history of affordability exemptions, however, in countries with social health insurance systems, such as Germany and the Netherlands. In both Germany and in the Netherlands, the affordability 
exemption applied to people whose income exceeded a normatively determined threshold. Those in this group were not compelled to purchase public insurance but could choose to purchase private substitute coverage or to remain uninsured.

As incomes rose in each of these countries, a growing share of the population exceeded the exemption income threshold. The substantial population exempt from public insurance coverage created the predictable problems described above: adverse selection against the public insurance coverage pool, poor decisionmaking around the purchase of coverage, and free-riding on the public insurance safety net. Both the Netherlands (in 2006) and Germany (in 2009) have now reformed their health insurance systems, mandating that everyone purchase coverage. In Germany, those with incomes above the affordability threshold may continue to choose private rather than public coverage. In the Netherlands, all residents may choose from among a range of competing plans. These examples suggest that mandate exemptions may be only a temporary fix in the design of health insurance systems. 


\section{$\underline{\text { References }}$}

Baglole, Joel. Getting the Gray Out; Canadian and U.S. regulators are looking to impose order on the sale of cheap online drugs. The Wall Street Journal, February 11, 2003 at R6.

Bradley, Ralph. Comment—Defining health insurance affordability: Unobserved heterogeneity matters. Journal of Health Economics. Vol. 27, 4, July 2008: 1129-1140

Budetti, John, Janet Shikles, Lisa Duchon and Cathy Schoen. Can't Afford to Get Sick: A Reality for Millions of Working Americans: The Commonwealth Fund 1999 National Survey of Workers' Health Insurance, The Commonwealth Fund, September 1999

Bundorf, M. Kate and Mark V. Pauly. Is health insurance affordable for the uninsured? Journal of health economics 25:44, 650-673, Elsevier, 2006

Fisher, Gordon M. The Development and History of the Poverty Thresholds. Social Security Bulletin. 1992. Vol. 55, number 4. p. 43-46.

Getzen, Thomas E. Health care is an individual necessity and a national luxury: applying multilevel decision models to the analysis of health care expenditures Journal of Health Economics, Vol. 19 (2): 259-270.

Gilmer, Todd and Richard Kronick. It's The Premiums, Stupid: Projections Of The Uninsured Through 2013. Health Affairs Web Exclusive, April 5, 2005

Glied, Sherry. "Is Something Better than Nothing? Health Insurance Expansions and the Content of Coverage,” in Frontiers in Health Policy Research, vol. 6, ed. D. Cutler and A. Garber (Cambridge,Mass: MIT Press, 2003), 55-86.

Gundersen, C., \& Gruber, J. (2001). The dynamic determinants of food insufficiency. In M. Andrews \& M. Prell (Eds.), Second Food Security Measurement and Research Conference (Vol. II, pp. 92-110). USDA, ERS FANR Report 11-2.

Hadley, J and JD Reschovsky. Tax credits and the affordability of individual health insurance. Issue Brief Cent Stud Health System Change, 2002.

Hadley, J. and J. Holahan, "How Much Medical Care Do the Uninsured Use, and Who Pays For It?” Health Affairs Web Exclusive (Feb. 12, 2003):w3-66-w3-81

Hall, Robert E. and Charles I Jones, 2007. "The Value of Life and the Rise in Health Spending," The Quarterly Journal of Economics, MIT Press, vol. 122(1), pages 39-72, 02.

Hancock, J.E., 1993. 'Can pay? Won’t pay?’ or economic principles of 'affordability.' Urban Studies 30(1), 127-145. 
Hansen, Julia L. , John P. Formby and W. James Smith. Estimating the Income Elasticity of Demand for Housing: A Comparison of Traditional and Lorenz-Concentration Curve Methodologies. Journal of Housing Economics, Vol. 7, Issue 4, December 1998: 328342.

Jacobs, Eva and Stephanie Shipp. How Family Spending Has Changed In The U.S. Monthly Labor Review; Mar 1990; 113, 3: 20-27.

Levy, Helen and Thomas DeLeire. “What Do People Buy When They Don’t Buy Health Insurance and What Does That Tell Us About Why They Are Uninsured?” July 2003, National Bureau of Economic Research Working Paper Series No. 9826.

Nyman, John A. "The Value of Health Insurance: The Access Motive," Journal of Health Economics, vol. 18, no. 2, April 1999, pp. 141-152

Quigley, John M, Steven Raphael. Is Housing Unaffordable? Why Isn't It More Affordable? The Journal of Economic Perspectives. Winter 2004. Vol. 18, Iss. 1, p. 191-214.

Renwick, Trudi J. and Barbara R. Bergmann. A Budget-Based Definition of Poverty: With an Application to Single-Parent Families. The Journal of Human Resources, Vol. 28, No. 1, (Winter, 1993), pp. 1-24.

Russell, Steven. Ability to Pay for Health Care: Concepts and Evidence. HEALTH POLICY AND PLANNING; 11(3): 219-237 @ Oxford University Press 1996

Thalmann, Philippe (1998). Identifying Households Which Need Housing Assistance. Urban Studies 36(11); 1933-1947.

Tobin, J. (1950), 'A statistical demand function for food in the U.S.A.', Journal of the Royal Statistical Society, Series A, t t 3 , 113-41. 


\begin{tabular}{|c|c|c|c|c|}
\hline & $\begin{array}{l}\text { Total health } \\
\text { spending } \\
<1.5 \% \text { of } \\
\text { income** }\end{array}$ & $\begin{array}{l}\text { Total health } \\
\text { spending }>30 \% \\
\text { of income** }\end{array}$ & $\begin{array}{l}\text { Out of pocket } \\
\text { health spending } \\
<1.5 \% \text { of } \\
\text { income }\end{array}$ & $\begin{array}{l}\text { Out of Pocket } \\
\text { health spending } \\
>30 \% \text { of } \\
\text { income }\end{array}$ \\
\hline \multicolumn{5}{|l|}{ Individuals } \\
\hline$<100 \% \mathrm{FPL}^{*}$ & 37.6 & 37.5 & 50.9 & 30.3 \\
\hline 100-124\% FPL & 45.8 & 28.8 & 59.2 & 23.3 \\
\hline 125-199\% FPL & 52.4 & 20.3 & 64.8 & 15.2 \\
\hline 200-399\% FPL & 53.8 & 15.2 & 67.0 & 12.4 \\
\hline $400 \%$ FPL + & 60.8 & 13.0 & 74.4 & 9.8 \\
\hline \multicolumn{5}{|l|}{ Families } \\
\hline$<100 \%$ FPL* & 37.1 & 18.2 & 58.1 & 9.1 \\
\hline 100-124\% FPL & 48.9 & 9.7 & 67.4 & 1.8 \\
\hline 125-199\% FPL & 50.6 & 6.8 & 66.3 & 1.5 \\
\hline 200-399\% FPL & 47.4 & 2.5 & 68.6 & 0 \\
\hline $400 \%$ FPL + & 59.0 & 5.9 & 80.5 & 2.5 \\
\hline \multicolumn{5}{|c|}{$\begin{array}{l}\text { Source: MEPS 2005. Family sample consists of families in which all members are full } \\
\text { year uninsured. *Families and individuals with incomes below } \$ 2000 \text { excluded. ** } \\
\text { Total spending estimates are adjusted for uncompensated care use using the methods } \\
\text { described in Hadley and Holahan, } 2003 \text {. }\end{array}$} \\
\hline
\end{tabular}




\begin{tabular}{|l|r|r|r|r|r|r|}
\hline Table 2: Adjusted Consumption Shares for US Families \\
\hline & 1950 & 1960 & 1972 & 1986 & 1996 & 2006 \\
\hline Health Care* & $4.4 \%$ & $5.3 \%$ & $7.4 \%$ & $10.0 \%$ & $12.6 \%$ & $14.5 \%$ \\
\hline Food & $29.9 \%$ & $24.6 \%$ & $19.1 \%$ & $14.2 \%$ & $12.7 \%$ & $11.4 \%$ \\
\hline Housing & $27.4 \%$ & $29.9 \%$ & $30.5 \%$ & $28.7 \%$ & $29.6 \%$ & $30.6 \%$ \\
\hline Transportation & $13.5 \%$ & $14.9 \%$ & $19.1 \%$ & $18.5 \%$ & $17.3 \%$ & $16.0 \%$ \\
\hline Clothing & $11.6 \%$ & $10.5 \%$ & $7.7 \%$ & $5.7 \%$ & $4.7 \%$ & $3.5 \%$ \\
\hline Other & $13.1 \%$ & $14.7 \%$ & $16.2 \%$ & $22.9 \%$ & $23.1 \%$ & $23.9 \%$ \\
\hline Source & &
\end{tabular}

Source: Consumption data from US Department of Labor, 100 Years of Consumer Spending: Data for the Nation, New York City, and Boston.

http://www.bls.gov/opub/uscs/. Data for 1996 from Table 26, 1984 from Table 23; 1972 from Table 20; 1960 from Table 17; 1950 from Table 14.

Health care as a share of GDP for 1960-2006 from National Health Accounts, CMS, http://www.cms.hhs.gov/NationalHealthExpendData/02_NationalHealthAccountsHistori cal.asp

*Health care as a share of GDP for 1950 from Stephen Joseph Williams and Paul Roger Torrens. Introduction to Health Services. Thomson Delmar Learning, 2001; Table 5.1 Data are adjusted by substituting health care as a share of GDP for consumption data medical care estimate and adjusting the denominator by subtracting the consumption data medical care share and adding the health care share of GDP. 


\section{Figure 1: Defining Affordability}

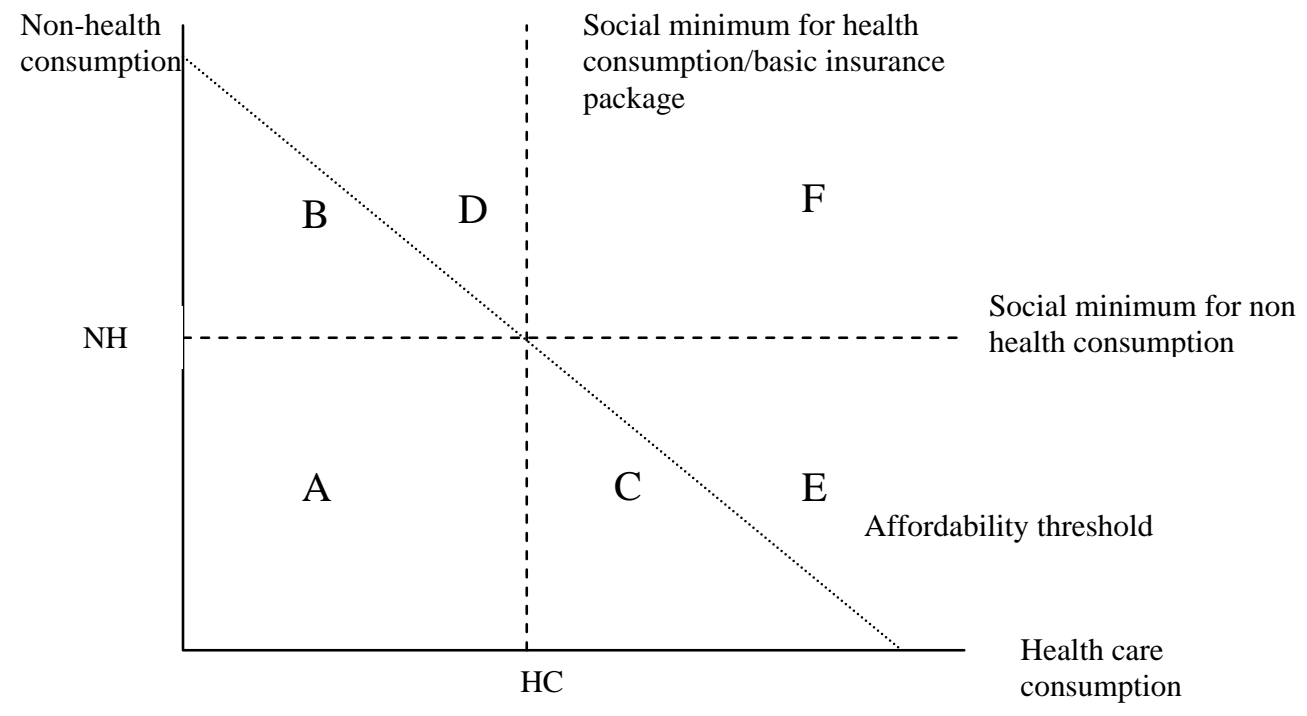

Based on Hancock, 1993. 